\section{Signs of asphyxia at birth and risk}

\section{of schizophrenia ${ }^{\dagger \dagger}$}

\author{
Population-based case-control study \\ CHRISTINA DALMAN, HOLLIE V. THOMAS, ANTONY S. DAVID, \\ JOHAN GENTZ, GLYN LEWIS and PETER ALLEBECK
}

\begin{abstract}
Background Previous research has found an association between obstetric complications and schizophrenia, but in many studies the sample size was limited, and no assessment of specific exposures was possible.
\end{abstract}

Aims To assess the role of different complications, and in particular to distinguish between disordered foetal development and hypoxia at birth.

Method From the Stockholm County In-Patient Register and community registers, we identified 524 cases of schizophrenia and 1043 controls, matched for age, gender, hospital and parish of birth. Data on obstetric complications were obtained from birth records.

Results There was a strong association between signs of asphyxia at birth and schizophrenia (OR 4.4; 95\% Cl 1.9-10.3) after adjustment for other obstetric complications, maternal history of psychotic illness and social class.

Conclusions Signs of asphyxia at birth are associated with an increased risk of schizophrenia in adults.

Declaration of interest No conflict of interest. The study was supported by the Stanley Foundation, the Swedish Medical Research Council and the Söderberg-Königska Foundation.

†See invited commentaries, pp. 4I5-416, this issue. ¥See pp. 409-414, this issue.
It has been suggested that foetal or neonatal damage to the central nervous system (CNS) could increase the risk of schizophrenia as an adult (Murray et al, 1985). In a meta-analysis of published research, Geddes \& Lawrie (1995) reported that schizophrenia was twice as likely in those with any obstetric complication, but also demonstrated evidence of publication bias. Furthermore, many previous studies have suffered from methodological problems such as: small sample size and lack of statistical power; reliance on summary scales of complications (Parnas et al, 1982; Lewis et al, 1989) which do not permit analysis of specific risk factors or aetiological mechanisms; and the use of maternal recall, which is prone to bias (Cantor-Graae et al, 1998). Finally, there has been little information on confounding factors, such as a maternal history of psychosis. We conducted a matched casecontrol study to examine the association between schizophrenia and obstetric complications, avoiding most of these problems. We distinguished between hypoxia occurring during delivery and abnormalities associated with foetal development.

\section{METHOD}

\section{Cases}

We used the Stockholm County In-Patient Register (Kristjansson et al, 1987) to identify all cases born in Stockholm since January 1960 who had been in-patients and had received a diagnosis of schizophrenia (ICD-8 and ICD-9 code 295; World Health Organization, 1967, 1978) between January 1971 and June $1994(n=648)$. Deaths $(n=51)$ and those who were not resident in Stockholm county $(n=32)$ were excluded. The parish of birth of the remaining 565 cases was obtained from local taxation offices. The birth hospital was located by contacting the parish. Only 37 $(6.5 \%)$ birth records could not be retrieved.

\section{Controls}

We selected, from the parish register, as controls, the next two births in time, of the same gender and born in the same hospital as the case. We used the personal identity number to check at the central taxation office that the person was still alive and resident in Stockholm County at the time of the selection of the cases. Eighty-nine birth records $(7.9 \%)$ could not be retrieved. For another four cases we could not get controls, owing to the small number of births in the parish, and these four were excluded, leaving 524 cases and 1043 controls.

\section{Birth records}

The 1567 birth records were copied from the archives and given code numbers to conceal case or control status. The first author (C.D.) selected and retrieved the birth records. The records were randomly assembled and given in batches to a midwife, who extracted data according to a protocol devised by the research group. Gestational age was based on date of mother's last menstruation (Tunón et al, 1996) or ultrasound when available. Small for gestational age (SGA) was defined as a foetal weight two standard deviations below Maršál et al's (1996) standard curves, based on 759 ultrasonic estimates of Scandinavian foetuses.

Signs of asphyxia were defined as an Apgar score of less than 7 at 1, 5 or 10 minutes (Sykes et al, 1982; Silverman et al, 1985). The Apgar score was introduced in the $1960 \mathrm{~s}$, hence only $20.5 \%$ of the records in this study had an Apgar score. All records with an Apgar score of 7 (six records) and below 7 (10 records) were examined by an experienced paediatrician (J.G.) to check the accuracy of the rating. Ten of these were judged to fulfil the criterion of an Apgar score below 7 . All records that lacked an Apgar scoring were assessed by the midwife according to a protocol in which the five Apgar items (heart rate, breathing, colour, tone and excitability of the infant) were defined. The records where the Apgar score was judged to be below 7 (44 records) were delivered to J.G. for further scrutiny. The reliability of the midwife's screening was tested in two ways: (a) a random sample of 300 birth records for infants classified as having no signs of asphyxia was reexamined by the first author, and none was classified as false negative; (b) a second 
midwife scrutinised blindly the records of all the 44 cases that were originally classified as having signs of asphyxia and a random sample of 120 classified as unaffected (in total, 164 birth records). The inter-record agreement was excellent ( $\kappa$ 0.95). J.G., blind to case/control status, estimated the expected Apgar score from the information in the 44 birth records and classified them into seven groups: Apgar $>6$ $(n=2)$, Apgar 4-6 at $1 \mathrm{~min}(n=25)$, Apgar $0-3$ at $1 \mathrm{~min}(n=5)$, Apgar $4-6$ at $5 \mathrm{~min}$ $(n=9)$, Apgar $0-3$ at 5 min $(n=0)$, Apgar $0-6$ at 10 -min $(n=1)$, unknown $(n=2)$. Altogether, 40 subjects were judged to have had an estimated Apgar score below 7. To test the reliability, another paediatrician assessed the 44 records. There was excellent agreement between the physicians in the classification into the seven groups above $(\kappa 0.83)$. When deciding whether the infants showed signs of asphyxia or not (i.e. Apgar score $<7$, or $\geqslant 7$ ), they disagreed in their assessment of only one subject.

As a result of these procedures, 50 subjects out of 1567 (3.1\%) were classified as having an Apgar score below 7. The proportion was the same among those whose Apgar ratings had been recorded $(3.1 \%)$ as among those who were assessed retrospectively $(3.2 \%)$. They were divided into slight (Apgar 4-6 at $1 \mathrm{~min}, n=32$ ) and moderate/severe asphyxia (Apgar score 03 at $1 \mathrm{~min}$ and $0-6$ at 5 and/or $10 \mathrm{~min}$, $n=18$ ).

Pre-eclampsia in the mother was defined as the presence of both proteinuria (more than traces on a single test, or repeated traces) and hypertension $(\geqslant 140 /$ 90 or $\geqslant 150 / 100 \mathrm{mmHg}$ on admission for delivery).

\section{Classification of obstetric complications}

The following a priori classification was used:

(a) Indicators of foetal growth impairment: pre-eclampsia, SGA, ponderal index $<25$ (weight $(\mathrm{g}) /$ length $\left(\mathrm{mm}^{3}\right)$ ), delay ( $>7$ days) in gaining weight after birth, birth weight, length and head circumference.

(b) Indicators of hypoxia/ischaemia around birth: emergency Caesarean section, placental abruption, cord prolapse, foetal heart rate $<100$ or $>160$ b.p.m., signs of asphyxia at birth (see above), and child remained in hospital (i.e. transferred from the maternity hospital to the children's hospital). Breech and foot presentation, long labour and instrumental delivery were weaker indicators.

We also noted other potentially important risk factors such as bilirubin measurements and any record of jaundice, as well as extreme prematurity (gestational age $<33$ weeks).

\section{Parental characteristics}

We recorded maternal age (in 5-year bands), parity $(1,2-3,4+)$, attendance at antenatal care (regular, none or irregular), civil status (married, unmarried or divorced). Socio-economic index (SEI) (Ericson et al, 1993a) was based on the highest SEI in the family: group I (SEI 5487)=upper-level executives, self-employed, professionals; group II (SEI 3347)=assistant non-manual employees; group III (SEI 11-22)=unskilled and skilled employees in goods and service production. Through a linkage with the National Inpatient Register we were able to identify mothers who had been admitted to hospital with a psychotic illness (295-299 ICD-8, 295-298 ICD-9) between 1971 and 1996.

\section{Statistical analysis}

Odds ratios (ORs) and 95\% confidence intervals (CIs) for schizophrenia in relation to individual obstetric complications were calculated for matched case-control sets using conditional logistic regression. Odds ratios were adjusted for possible confounding variables, both one by one and simultaneously. A similar method was used to study the continuous variables, in quintile

Table I Odds ratios for schizophrenia in relation to indicators of foetal growth impairment and short gestational age

\begin{tabular}{|c|c|c|c|c|}
\hline Variable & No. of cases & No. of controls & Odds ratio & $(95 \% \mathrm{Cl})$ \\
\hline \multicolumn{5}{|l|}{ Pre-eclampsia } \\
\hline No & 513 & 1029 & 1.0 & \\
\hline Yes & II & 14 & 1.6 & $(0.7-3.5)$ \\
\hline \multicolumn{5}{|c|}{ Birth length $(\mathrm{cm})$} \\
\hline$<49$ & 89 & 163 & I.I & $(0.8-1.5)$ \\
\hline $49-55$ & 422 & 849 & 1.0 & \\
\hline $55+$ & 12 & 30 & 0.8 & $(0.4-1.6)$ \\
\hline \multicolumn{5}{|c|}{ Head circumference $(\mathrm{cm})$} \\
\hline$<32$ & 42 & 67 & 1.3 & $(0.9-2.0)$ \\
\hline $32-37$ & 449 & 917 & 1.0 & \\
\hline $38+$ & 29 & 53 & 1.2 & $(0.6-2.4)$ \\
\hline \multicolumn{5}{|c|}{ Birth weight (g) } \\
\hline $0-2499$ & 25 & 29 & 1.8 & $(1.0-3.1)$ \\
\hline $2500-4499$ & 491 & 983 & 1.0 & \\
\hline $4500+$ & 8 & 31 & 0.5 & $(0.2-1.2)$ \\
\hline \multicolumn{5}{|c|}{ Ponderal index $\left(\mathrm{g} / \mathrm{mm}^{3}\right)$} \\
\hline$<25$ & 108 & 213 & 1.0 & $(0.8-1.3)$ \\
\hline $25+$ & 415 & 829 & 1.0 & \\
\hline \multicolumn{5}{|c|}{ Gestation (weeks) } \\
\hline$<33$ & 6 & 5 & 2.7 & $(0.7-9.7)$ \\
\hline $33-36$ & 30 & 55 & I.I & $(0.7-1.8)$ \\
\hline $37-42$ & 461 & 940 & 1.0 & \\
\hline $43+$ & 26 & 42 & 1.3 & $(0.8-2.0)$ \\
\hline \multicolumn{5}{|c|}{ Small for gestational age } \\
\hline No & 474 & 967 & 1.0 & \\
\hline Yes & 32 & 40 & 1.5 & $(0.9-2.4)$ \\
\hline \multicolumn{5}{|c|}{ Delay in gaining weight after birth (days) } \\
\hline $0-7$ & 459 & 940 & 1.0 & \\
\hline 8-20 & 23 & 25 & 1.9 & $(1.0-3.4)$ \\
\hline
\end{tabular}

Odds ratios estimated by conditional logistic regression for matched case-control sets. 
Table 2 Odds ratios for schizophrenia in relation to indicators of hypoxia at birth

\begin{tabular}{|c|c|c|c|c|}
\hline Complication & No. of cases & No. of controls & Odds ratio & $(95 \% \mathrm{Cl})$ \\
\hline \multicolumn{5}{|l|}{ Presentation } \\
\hline Normal & 476 & 957 & 1.0 & \\
\hline Breech and foot presentation & 16 & 31 & 1.1 & $(0.6-2.0)$ \\
\hline \multicolumn{5}{|l|}{ Labour (hours) } \\
\hline $0-12$ & 483 & 951 & 1.0 & \\
\hline$>12$ & 40 & 91 & 0.9 & $(0.6-1.3)$ \\
\hline \multicolumn{5}{|l|}{ Instrumental delivery' } \\
\hline No & 489 & 972 & 1.0 & \\
\hline Yes & 33 & 65 & 1.0 & $(0.6-1.5)$ \\
\hline \multicolumn{5}{|l|}{ Foetal heart rate } \\
\hline Normal & 490 & 987 & 1.0 & \\
\hline$<100$ or $>160$ b.p.m. & 18 & 39 & 1.0 & $(0.5-1.7)$ \\
\hline \multicolumn{5}{|l|}{ Asphyxia at birth ${ }^{2}$} \\
\hline No signs of asphyxia & 494 & 1015 & 1.0 & \\
\hline Signs of asphyxia & 28 & 22 & 2.7 & (I.5-4.8) \\
\hline \multicolumn{5}{|l|}{ Child remained in hospital } \\
\hline No & 475 & 981 & 1.0 & \\
\hline Yes & 46 & 55 & 1.7 & $(1.2-2.6)$ \\
\hline
\end{tabular}

Odds ratios estimated by conditional logistic regression for matched case-control sets.

I. Instrumental delivery includes use of forceps, vacuum extraction and Caesarean section.

2. Signs of asphyxia based on complications expected to yield an Apgar score $<7$ at I, 5 or 10 min.

groups, but we also examined the statistical significance of quadratic functions using likelihood ratio tests.

\section{RESULTS}

\section{Characteristics of schizophrenia cases and control subjects}

The mean age of the cases at diagnosis was 24.7 years (range 9-34 years). There were 173 cases with early age of onset of schizophrenia ( $<23$ years), 160 cases in whom the onset was between 23 and 27 years of age and 191 with an onset later than 27 but before 35 years of age (the upper limit, determined by the end of the follow-up period). Sixty-seven per cent of cases were male. Unmarried or divorced mothers formed $18.9 \%$ of the mothers of cases and $17.0 \%$ of mothers of controls. A higher proportion of the mothers of cases than of controls received no, or irregular, antenatal care $(5.1 \% \quad v .3 .4 \%)$ and had a history of psychotic illness $(9.2 \%$ v. $1.7 \%)$. Maternal history of psychotic illness was strongly associated with the risk of schizophrenia (OR 5.8; 95\% CI 3.3-10.3). First-born children formed $43 \%$ of cases and controls. There were no significant differences between cases and controls regarding socio-economic classification.

\section{Associations between individual obstetric complications}

Subjects with one complication were more likely to have another complication. For example, $20.0 \%$ of subjects who had shown signs of asphyxia at birth, and $21.3 \%$ of subjects who were breech presentations during labour, also had a birth weight below $2500 \mathrm{~g}$.

\section{Odds ratios for schizophrenia in relation to indicators of foetal growth impairment and short gestational age}

Those who were SGA (OR 1.5; 95\% CI 0.9-2.4), showed delay in gaining weight after birth (OR 1.9; 95\% CI 1.0-3.4) or whose mothers had had pre-eclampsia (OR 1.6; 95\% CI 0.7-3.5) all showed trends towards greater risk of schizophrenia, although this was not statistically significant (Table 1). The odds ratio for schizophrenia in subjects whose birth weight was less than $2500 \mathrm{~g}$ was 1.8 (95\% CI 1.0-3.1). Adjusting for length of gestation barely affected the odds ratios in relation to birth weight, birth length, ponderal index and head circumference. The odds ratio for schizophrenia in those who had extremely short gestational age ( $<33$ weeks) was 2.7 (95\% CI 0.7-9.7) (Table 1).

Odds ratios were also calculated for the continuous variables (birth weight, birth length, ponderal index, head circumference, gestation length), using the distribution among the controls divided into fifths. None of these variables, when analysed in this manner, was demonstrated to be associated with risk of schizophrenia. A quadratic model did not significantly improve the fit of the data. For example, the odds ratio for birth weight in quintile groups was 1.0 (95\% CI 1.0-1.1). There was no statistically significant relationship with birth weight when a quadratic term was included ( $\chi^{2}=1.05$, d.f. $\left.=2, P=0.59\right)$.

\section{Odds ratios for schizophrenia in relation to indicators of hypoxia at birth}

There was an increased risk of schizophrenia in subjects who had signs of asphyxia at birth (OR 2.7; 95\% CI 1.54.8) (Table 2). The odds ratios were about the same when divided into slight (OR 2.6; 95\% CI 1.3-5.3) or moderate to severe asphyxia (OR 2.8; 95\% CI 1.0-7.4). Children who had to remain in hospital were also at increased risk for schizophrenia. There were too few cases of emergency Caesarean sections, placental abruption and cord prolapse to perform meaningful analysis for these factors. Foetal heart rate $<100$ or $>160$ b.p.m. was not associated with increased risk, nor were the weaker indicators (breech and foot presentation, labour lasting more than 12 hours and instrumental delivery).

\section{Odds ratios for schizophrenia in relation to other obstetric risk factors}

The obstetric records also provided data on jaundice at birth, although the number of subjects for whom bilirubin measurements were thought necessary was small $(n=140)$. A bilirubin measurement of $15 \mathrm{mg} \%$ or more, in comparison to having no record of jaundice, was demonstrated to be associated with an increased risk of schizophrenia (OR 2.1; 95\% CI 1.1-3.7). After adjustments for confounders and other birth and pregnancy variables (as in 
Table 3 Adjusted odds ratios for schizophrenia

\begin{tabular}{|c|c|c|c|}
\hline \multirow[t]{2}{*}{ Complication } & \multicolumn{3}{|c|}{ Odds ratio $(95 \% \mathrm{Cl})$} \\
\hline & Unadjusted & $\begin{array}{l}\text { Adjusted for possible } \\
\text { confounders' }\end{array}$ & $\begin{array}{c}\text { Adjusted for other } \\
\text { obstetric complications }{ }^{2}\end{array}$ \\
\hline \multicolumn{4}{|l|}{ Pre-eclampsia } \\
\hline No & 1.0 & 1.0 & 1.0 \\
\hline Yes & $1.6(0.7-3.5)$ & $1.9(0.8-5.0)$ & $0.9(0.3-3.0)$ \\
\hline \multicolumn{4}{|l|}{ Birth weight (g) } \\
\hline $0-2499$ & $1.8(1.0-3.1)$ & $1.4(0.7-2.8)$ & $0.7(0.2-2.0)$ \\
\hline $2500-4499$ & 1.0 & 1.0 & 1.0 \\
\hline $4500+$ & $0.5(0.2-1.2)$ & $0.6(0.2-1.5)$ & $0.5(0.2-1.4)$ \\
\hline \multicolumn{4}{|l|}{ Gestation (weeks) } \\
\hline$<33$ & $2.7(0.7-9.7)$ & $2.2(0.6-8.7)$ & I.I (0.2-6.2) \\
\hline $37-42$ & 1.0 & 1.0 & 1.0 \\
\hline \multicolumn{4}{|l|}{ Small for gestational age } \\
\hline No & 1.0 & 1.0 & 1.0 \\
\hline Yes & $\mathrm{I} .5(0.9-2.4)$ & $1.5(0.9-2.6)$ & $1.0(0.5-2.0)$ \\
\hline \multicolumn{4}{|c|}{ Delay in gaining weight after birth (days) } \\
\hline $0-7$ & 1.0 & 1.0 & 1.0 \\
\hline $8-20$ & $1.9(1.0-3.4)$ & $1.6(0.8-3.3)$ & $1.3(0.6-3.0)$ \\
\hline \multicolumn{4}{|l|}{ Asphyxia at birth ${ }^{3}$} \\
\hline No signs of asphyxia & 1.0 & 1.0 & 1.0 \\
\hline Signs of asphyxia & $2.7(1.5-4.8)$ & $4.5(2.2-9.5)$ & $4.4(1.9-10.3)$ \\
\hline \multicolumn{4}{|c|}{ Child remained in hospital } \\
\hline No & 1.0 & 1.0 & 1.0 \\
\hline Yes & $1.7(1.2-2.6)$ & $1.7(I .1-2.8)$ & $1.5(0.8-2.9)$ \\
\hline
\end{tabular}

Odds ratios estimated by conditional logistic regression for matched case-control sets.

I. Possible confounders are maternal history of psychotic illness (code 295-299 ICD-8 or 295-298 ICD-9 in Swedish National In-Patient Register 197I-1996), maternal age (<20, 20-24, 25-29, 30-34, 35-39, 40+), parity (I, 2-3, 4+), socio-economic classification (Group I i.e. professionals, Group II or III i.e. manual and non-manual employees), civil status (married, unmarried or divorced) and attendance to antenatal care (regular, none or irregular).

2. Adjusted for possible confounders and further adjusted simultaneously for all other complications listed in Table 3.

3. Signs of asphyxia based on complications expected to yield an Apgar score $<7$ at I, 5 or $10 \mathrm{~min}$.

the last column of Table 3) this point estimate was unchanged (OR 2.0; $95 \%$ CI $0.8-5.4)$, although no longer statistically significant.

\section{Adjusted odds ratios for schizophrenia}

Table 3 presents the adjusted odds ratios for those complications which were demonstrated to have an odds ratio for schizophrenia $>1.5$ or $<0.7$ from Tables 1 and 2. Adjusting either separately or simultaneously for maternal history of psychotic illness, maternal age, parity, socio-economic classification, civil status and attendance at antenatal care did not substantially alter the odds ratios for most of the obstetric complications listed. However, after adjusting for these possible confounding

\section{DISCUSSION}

\section{Main findings}

In this study we found an association with schizophrenia for indicators of foetal growth impairment as well as indicators of hypoxia at birth, before taking possible confounders into account. Signs of asphyxia at birth (Apgar score <7), the need for the child to remain in hospital, low birth weight $(<2500 \mathrm{~g})$, and delay in gaining weight after birth were all associated with significantly increased risk. Pre-eclampsia, SGA and short gestational age ( $<33$ weeks) showed increased risk estimates but were not statistically significant. After adjustments for possible confounding factors, including other obstetric complications, only signs of asphyxia at birth, judged by paediatricians as an Apgar score less than 7 , remained significantly associated with an increased risk for schizophrenia (OR 4.4; 95\% CI 1.9-10.3). From our study we conclude that signs of asphyxia at birth are independently associated with schizophrenia.

Our results are in accordance with previous findings that foetal distress (O’Callaghan et al, 1992), high scores on risk of asphyxia scale (Günther-Genta et $a l, 1994)$ and use of resuscitation (Geddes et al, 1999), often related to low Apgar scores, are associated with an increased risk of schizophrenia. In three population-based studies (Jones et al, 1998; Dalman et al, 1999; Hultman et al, 1999) there was a trend towards increased frequency of low Apgar scores among infants who later developed schizophrenia, although the association was not statistically significant. Jones et al (1998) did not adjust for other complications of pregnancy and birth, although the unadjusted results indicated associations with birth factors that are consistent with our data. The two Swedish studies (Dalman et al, 1999; Hultman et $a l, 1999)$ did not adjust for socio-economic status, which appeared to increase the association with asphyxia in our study. Another reason for the discrepancy between these two studies and our present one may be that their investigations were restricted to cases with onset before 23 years of age, since aetiological mechanisms might differ between different ages of onset. One further difference was that in our study asphyxia was rated by paediatricians and based on actual birth records, rather than relying upon register data from a large number of sources. 
There was no evidence of any independent association between continuous measures of foetal size, including foetal length, head circumference, ponderal index and foetal weight, even after adjustments for gestational age. These measures have been widely interpreted as indicators of foetal development, including foetal brain development, and of a satisfactory intrauterine environment. These indices may be of no relevance in this context or too blunt.

A weak association was also found between jaundice, defined as hyperbilirubinaemia (>15 $\mathrm{mg} \%$ ), and subsequent schizophrenia. This has not been found in the majority of studies, but has previously been described (Hollister et al, 1996; Dalman \& Cullberg, 1999). In the present study we did not rely on a diagnosis of jaundice in the birth records but made use of serum bilirubin levels collected at the time, which may explain our finding.

\section{Strengths of the study}

The study was large, and identified people with schizophrenia from a populationbased register, hence it was relatively free from selection bias. The obstetric information was collected at birth and measured without recall bias in relation to case-control status. We were able to ensure that controls were resident in Stockholm at the time that the cases were identified, thus further reducing any possibility of selection bias. Finally, we were able to adjust for a number of confounding factors. By matching for hospital of birth, we could take account of any hospital variation in coding the complications. There is also a geographical variation in rates of birth complications and schizophrenia (Ericson et al, 1993b; Mortensen et al, 1999), so we also matched for parish of birth. Finally, we also adjusted for attendance at antenatal care, social class at birth (SEI classification and civil status) and maternal psychotic illness, which are potential confounders.

\section{Limitations of the study}

There may be some confounding factors on which we have no data: for example, maternal substance misuse. We relied upon clinical diagnosis of schizophrenia, although the validity of diagnosis in Sweden is high, with a sensitivity of $85 \%$ in one study (Kristjansson et al, 1987). Signs of asphyxia were assessed by clinicians from case records rather than

\section{CLINICAL IMPLICATIONS}

- We confirmed previous findings of an association between obstetric complications and the later development of schizophrenia.

Minimising the occurrence of asphyxia and subsequent states of hypoxia/ischaemia may be important to prevent mental illness.

More knowledge about the background factors for schizophrenia may make it possible to search for preventive strategies.

\section{LIMITATIONS}

Even though the sample size was large, it was still not sufficient to analyse rare obstetric risk factors.

- Indicators of asphyxia were obtained through retrospective coding of birth records.

- Different complications are interrelated and thus the causal pathways may be difficult to discern.

CHRISTINA DALMAN, MD, Community Medicine, Unit for Psychosis Research, Stockholm, Sweden;

HOLLIE V. THOMAS, DPhil, University of Wales College of Medicine, Cardiff; ANTONY S. DAVID, FRCPsych, Institute of Psychiatry and GKT School of Medicine, London; JOHAN GENTZ, MD, Sachsska Children's Hospital, Stockholm, Sweden; GLYN LEWIS, FRCPsych, University of Wales College of Medicine, Cardiff; PETER ALLEBECK, MD, Department of Social Medicine, Göteborg University, Sweden

Correspondence: Christina Dalman, MD, Community Medicine, Unit for Psychosis Research, PO Box 175 33, S-II8 91 Stockholm, Sweden. E-mail: christina.dalman@smd.sll.se

(First received 22 June 1999, final revision 27 January 2000, accepted 27 January 2000)

more directly recorded at time of birth. Nevertheless, this assessment was blind to case-control status and was shown to be reliable. Any random misclassification should have reduced the association. The Apgar score itself is an imperfect measure of asphyxia and the resulting state of hypoxia (Sykes et al, 1982; Silverman et $a l, 1985)$, and for that reason we restricted the classification to slight and moderate/ severe signs of asphyxia. Despite the large size of the sample, some of the complications we studied were uncommon and the confidence intervals relatively broad. In particular, our results are compatible with important associations between schizophrenia and pre-eclampsia, low birth weight, hyperbilirubinaemia and prematurity.

\section{Possible mechanisms}

Our results support a relationship between hypoxia at birth and schizophrenia, but some of the indicators of foetal disturbances (for example, pre-eclampsia and prematurity) could not be dismissed as risk factors for schizophrenia. It is difficult to deduce causal mechanisms from complications of birth and pregnancy. Disorders of pregnancy, such as pre-eclampsia, could reduce the supply of nutrients, including glucose and oxygen (intra-uterine hypoxia), which would interfere with brain development (Dobbing, 1979). In contrast, an infant who has developed normally may experience relatively short-term insult around the time of birth because of hypoxia. Hypoxic brain damage is particularly seen in the brain-stem nuclei, hippocampus and cortex (Volpe, 1995) and is thought to be caused by acidosis and waste products, including amino acids and free radicals (Kjellmer \& Hagberg, 1994; Volpe, 1995). N-methyl-D-aspartate receptors (NMDA receptors) are considered to play a key role (Volpe, 1995). Reduced 
volume of the hippocampus has recently been described in schizophrenia patients with a history of obstetric complications (Stefanis et al, 1999). Greater understanding of the effect of hypoxia on brain development and adult brain function will probably help us to understand more about the pathogenesis of schizophrenia.

\section{ACKNOWLEDGEMENTS}

We thank Professor Johan Cullberg, MD, for valuable comments, Birger Winblad, MD, for assessing records and Charlotta Grunewald, MD, for obstetric advice. We also thank Dr Karin Nyberg for sharing her knowledge on obstetric case records and working routines. We are grateful to Aslög Malmberg, MRCPsych, for help in designing the study and to the midwives Gunilla Lilja and Åsa Weitzberg for assessing records.

\section{REFERENCES}

Cantor-Graae, E., Cardinal, S., Ismail, B., et al (1998) Recall of obstetric events by mothers of schizophrenic patients. Psychological Medicine, 28, 1239-1243.

Dalman, C. \& Cullberg, J. (1999) Neonatal hyperbilirubinaemia - a vulnerability factor for mental disorder? Acta Psychiatrica Scandinavica, 100, 469-47I.

_ , Allebeck, P., Cullberg, J., et al (1999) Obstetric complications and the risk of schizophrenia. Archives of General Psychiatry, 56, 234-240.

Dobbing, J. (1979) Nutrition and brain development. In Perinatal Medicine (eds O. Thallummer, K. Baumgarten \& A. Pollak) (6th European Congress, Vienna). Stuttgart: Thieme.

Ericson, A., Eriksson, M., Kjällén, B., et al (1993a) Methods for the evaluation of social effects of birth weight - experiences with Swedish population registries. Scandinavian Journal of Social Medicine, 2I, 69-76. $\ldots, \ldots$, , et al (1993b) Secular trends in the effect of socio-economic factors on birth weight and infant survival in Sweden. Scandinavian Journal of Social Medicine, 21, 10-16.

Geddes, J. R. \& Lawrie, S. M. (1995) Obstetric complications and schizophrenia: a meta-analysis. British Journal of Psychiatry, 167, 786-793.

_ , Verdoux, H., Takei, N., et al (1999) Schizophrenia and complications of pregnancy and labour: an individual patient data meta-analysis. Schizophrenia Bulletin, 25 413-423.

Günther-Genta, F., Bovet, P. \& Hohlfeld, P. (1994) Obstetric complications and schizophrenia. A casecontrol study. British Journal of Psychiatry, 164, 165-170.

Hollister, M. J., Laing, P., Sarnoff, A., et al (1996)

Rhesus incompatibility as a risk factor for schizophrenia in male adults. Archives of General Psychiatry, 53, 19-24.

Hultman, C. M., Sparén, P., Takei, N., et al (1999)

Prenatal and perinatal risk factors for schizophrenia, affective psychosis, and reactive psychosis of early onset: case-control study. British Medical Journal, 318 $421-426$.

Jones, P. B., Rantakallio, P., Hartikainen, A-L., et al (1998) Schizophrenia as a long-term outcome of pregnancy, delivery, and perinatal complications: a 28-year follow-up of the 1966 north Finland general population birth cohort. American Journal of Psychiatry, I55, 355-364.

Kjellmer, I. \& Hagberg, H. (1994) Perinatal brain damage related to excitatory amino acids and oxygen free radicals. In A Critical Appraisal of Fetal Surveillance (eds H. P. van Geijn \& F. J. A. Copray), pp. 604-614. Amsterdam: Excerpta Medica.

Kristjansson, E., Allebeck, P. \& Wistedt, B. (1987) Validity of the diagnosis schizophrenia in a psychiatric inpatient register. Nordic Journal of Psychiatry, 4I, 229-234.

Lewis, S. W., Owen, M. J. \& Murray, R. M. (1989) Obstetric complications and schizophrenia: methodology and mechanisms. In Schizophrenia: Scientific Progress (eds S. C. Schulz \& C. A. Tamminga), pp. 56-68. New York: Oxford University Press.

Maršál, K., Persson, P-H., Larsen, T., et al (1996) Intrauterine growth curves based on ultrasonically estimated foetal weights. Acta Paediatrica, 85 843-848.

Mortensen, P. B., Pedersen, C. B., Westergaard, T. et al (1999) Effects of family history, and place of birth on the risk of schizophrenia. New England Journal of Medicine, 340, 603-608.

Murray, R. M., Lewis, S. W. \& Reveley, A. M. (1985) Towards an aetiological classification of schizophrenia. Lancet, 4I, 1023-1026.

O'Callaghan, E., Gibson, T., Colohan, H. A., et al (1992) Risk of schizophrenia in adults born after obstetric complications and their association with early onset of illness: a controlled study. British Medical Journal, 305, 1256-1259.

Parnas, J., Schulsinger, F., Teasdale, T.W., et al (1982) Perinatal complications and clinical outcome with the schizophrenia spectrum. British Journal of Psychiatry, 140 416-420.

Rothman, K. J. (1986) Modern Epidemiology. Boston: Little Brown

Silverman, F., Suidan, J., Wasserman, J., et al (1985) The Apgar score: is it enough? American Journal of Obstetrics and Gynecology, 66, 33I-336.

Stefanis, N., Frangou, S., Yakeley, J., et al (1999) Hippocampal volume reduction in schizophrenia: effects of genetic risk and pregnancy and birth complications. Biological Psychiatry, 46, 697-702.

Sykes, G. S., Johnson, P., Ashworth, F., et al (1982) Do Apgar scores indicate asphyxia? Lancet, 27, 494-496.

Tunón, K., Eik-Nes, S. H. \& Grøttum, P. (1996) A comparison between ultrasound and a reliable last menstrual period as predictors of the day of delivery in 15000 examinations. Ultrasound in Obstetrics and Gynecology, 8, 178-185.

Volpe, J. J. (1995) Neurology of the Newborn (3rd edn) Philadelphia: Saunders.

World Health Organization (1967) Manual of the International Statistical Classification of Diseases, Injuries and Causes of Death (8th revision) (ICD-8). Geneva: WHO.

- (1978) Manual of the International Statistical Classification of Diseases, Injuries and Causes of Death (9th revision) (ICD-9). Geneva: WHO. 